Article

\title{
Optimal Distribution of Renewable Energy Systems Considering Aging and Long-Term Weather Effect in Net-Zero Energy Building Design
}

\author{
Yuehong Lu ${ }^{1}$, Mohammed Alghassab ${ }^{2}$, Manuel S. Alvarez-Alvarado ${ }^{3}$, Hasan Gunduz ${ }^{4} \oplus$, \\ Zafar A. Khan ${ }^{5, *}$ and Muhammad Imran ${ }^{6}$ D \\ 1 Department of Civil Engineering and Architecture, Anhui University of Technology, \\ Ma'anshan 243002, China; luyuehongtuzi@163.com \\ 2 Department of Electrical and Computer Engineering, Shaqra University, Riyadh 11911, Saudi Arabia; \\ malghassab@su.edu.sa \\ 3 Faculty of Engineering in Electricity and Computing, Escuela Superior Politécnica del Litoral, \\ Guayaquil EC 09-01-5863, Ecuador; manuel.alvarez.alvarado@ieee.org \\ 4 Department of Electricity and Energy, Mus Alparslan University, Mus 49250, Turkey; hasangunduz@ieee.org \\ 5 Department of Electrical Engineering, Mirpur University of Science and Technology, \\ Mirpur (A.K.) 10250, Pakistan \\ 6 School of Engineering and Applied Science, Mechanical Engineering and Design, Aston University, \\ Birmingham B4 7ET, UK; m.imran12@aston.ac.uk \\ * Correspondence: zafarakhan@ieee.org
}

Received: 28 May 2020; Accepted: 7 July 2020; Published: 10 July 2020

\begin{abstract}
Generation system interruptions in net-zero energy buildings (NZEBs) may result in missing the net-zero targets by a great margin. Consequently, it is significant to incorporate a realistic reliability model for renewable energy systems (RESs) that considers aging and long-term weather conditions. This study proposed a robust design optimization method that deals with the selection of RES to achieve NZEB. Different case studies were evaluated: 1 . Deterministic approach; 2. Markov chain-based reliability without the aging effect; 3 . Markov chain-based reliability with the aging effect. The results showed that the optimal sizes of RES, considering the aging effect, were much larger than the other two cases based on the annual energy balance. Moreover, the consideration of the aging effect on the reliability assessment of the generation system for NZEB opens a pathway for a more robust and economic design of RES.
\end{abstract}

Keywords: aging effect; Markov chain model; Monte Carlo simulation; net-zero energy building

\section{Introduction}

Net-zero energy buildings (NZEBs) have been widely recognized as a promising way to solve the energy crisis and environmental problems. The topic has become so significant that nowadays a range of supporting policies and a financial incentive have been provided for the development of the NZEB in different countries. In Europe, the goal of "nearly net-zero energy buildings" has been established for all the new buildings from 2020 [1]. In the USA, a net-zero energy target for all new residential buildings by 2020 and for all new commercial buildings by 2030 has been set by the California Public Utilities Commission [2]. Substantial research has been conducted on how to design a NZEB in an economic and efficient way. In general, three approaches have been identified to be key factors for achieving NZEB: (1) passive design strategy (e.g., building orientation, cooling/heating strategy) [3,4]; (2) energy efficiency technologies (e.g., HVAC, lighting, and appliances) [5,6]; (3) energy production technologies (e.g., combined cooling, heat and power, battery, photovoltaic panel, and wind 
turbine) $[7,8]$. A schematic diagram of the approaches is shown in Figure 1. The literature presents many models on NZEB, for instance, the investigation conducted by Thalfeldt et al. [3] on optimal cost solutions regarding building facade solutions (i.e., the ratio of window-to-wall, external wall insulation, window properties, and shading) for nearly zero energy buildings. Wu et al. [5] investigated HVAC technologies for a residential NZEB in order to achieve the target of energy-saving, cost-effective, and comfortable indoor environment. In the study of Lu et al. [7], the selection of RES was conducted using a single-objective method based on genetic algorithm and multi-objective optimization method based on non-dominated sorting genetic algorithm (NSGA-II) for low/zero energy buildings, respectively. Figure 1 presents a classification of the main approaches to achieve NZEB.

Considering deterministic methods of analysis may not predict the levelized cost of energy accurately, Maheri [10] proposed two algorithms to find the optimum margin of safety concerning the system reliability by the Monte Carlo simulation for standalone hybrid PV-wind diesel systems. In the study of Lu et al. [11], a penalty cost function was introduced for the NZEB design, and the potential benefits for investors were investigated by comparing with the case under no financial support. Many of the studies have considered the effect of uncertain parameters on system selection for NZEB and its performance. The uncertainties were mainly focused on building energy consumption (physical parameters, design parameters, scenario parameters) $[9,12,13]$ and renewable sources (i.e., solar radiation, wind velocity, and biodiesel price) [11,14,15]. As indicated by Huang et al. [16], most of the present studies related to NZEB ignore component degradation and maintenance. Therefore, they proposed a robust design of NZEB systems by considering system degradation (i.e., HVAC system, generation system, and energy storage system) and maintenance. However, the effect of the reliability of generation units (considering failure and the aging effect) on the selection of RES for NZEB still needs to be investigated.

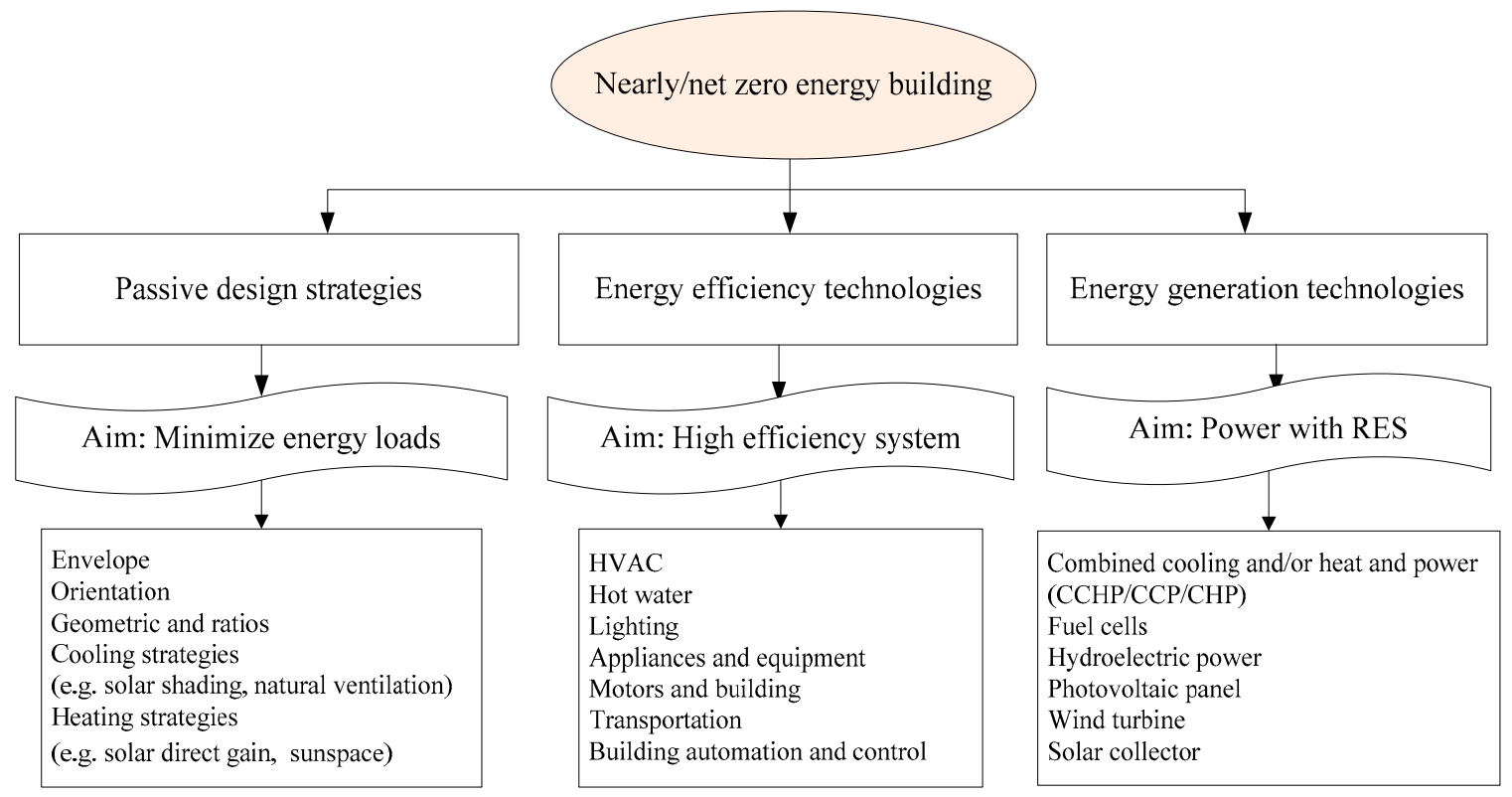

Figure 1. Main approaches to achieve net-zero energy buildings (NZEBs). RES: renewable energy system.

The carbon reduction targets and integration of new technologies have shifted the focus of the research mainly on the installation of RES in NZEB. However, how to select an appropriate generation system to achieve NZEB is an interesting field that attracts many researchers. A summary of design methodologies and generation system combinations is listed in Table 1. For instance, Zhang et al. [9] proposed a response-surface-model-based system sizing method that aims to reduce the number of the Monte Carlo simulation, and it was confirmed to work satisfactorily for the energy performance of NZEB. 
Table 1. Summary of the design optimization of generation systems for NZEB. (WT-Wind turbine, BDG-Biodiesel generator, TES-Thermal energy system, EES-Electrical energy storage, SDHW- solar domestic hot water, COP-Coefficient of performance).

\begin{tabular}{|c|c|c|c|}
\hline Ref. & $\begin{array}{l}\text { Energy Production } \\
\text { System }\end{array}$ & $\begin{array}{l}\text { Uncertainty/Reliability } \\
\text { Analysis }\end{array}$ & Factors Considered for Reliability Analysis \\
\hline [7] & PV/WT/BDG & $\mathrm{N}$ & None \\
\hline [8] & $\begin{array}{c}\text { PV/WT, PV/BDG, } \\
\text { WT/BDG, PV/WT/BDG }\end{array}$ & Y & $\begin{array}{c}\text { Solar radiation, wind velocity, cooling load, other } \\
\text { electricity load. }\end{array}$ \\
\hline [9] & PV/WT/Battery & Y & $\begin{array}{l}\text { Physical parameters (e.g., U value of window, } \\
\text { shading coefficient), design parameters } \\
\text { (e.g., occupant number, light ratio), scenario parameters } \\
\text { (e.g., ambient temperature, ambient relative humidity). }\end{array}$ \\
\hline [10] & PV/WT/BDG & Y & $\begin{array}{l}\text { Solar radiation, wind speed, demand load, wind turbine } \\
\text { power coefficient model, PV array efficiency. }\end{array}$ \\
\hline [11] & $\mathrm{PV} / \mathrm{WT} / \mathrm{BDG}$ & Y & $\begin{array}{l}\text { Solar radiation, wind velocity, cooling load, other } \\
\text { electricity load. }\end{array}$ \\
\hline [12] & PV/WT/TES/EES & Y & $\begin{array}{l}\text { Ambient temperature, relative humidity, solar radiation, } \\
\text { and wind speed. }\end{array}$ \\
\hline [13] & PV/WT & Y & $\begin{array}{l}\text { Physical parameters (e.g., U value of window, shading } \\
\text { coefficient), design parameters (e.g., occupant number, } \\
\text { light ratio), scenario parameters (e.g., ambient } \\
\text { temperature, ambient relative humidity). }\end{array}$ \\
\hline [14] & PV/WT/BDG & Y & $\begin{array}{c}\text { Solar radiation, wind velocity, cooling load, other } \\
\text { electricity load. }\end{array}$ \\
\hline [15] & PV/WT/Battery & Y & $\begin{array}{l}\text { Solar radiation, wind speed, and demand load. } \\
18 \text { scenario parameters (e.g., occupant density, infiltration } \\
\text { rate, solar radiation), } 5 \text { design parameters }\end{array}$ \\
\hline [16] & PV/WT/Battery & Y & $\begin{array}{c}\text { (e.g., window/wall thermal resistance, chiller capacity, and } \\
\text { COP), degradation parameters of HVAC system, PV array, } \\
\text { WT, energy storage system. }\end{array}$ \\
\hline [17] & PV/WT/Battery & Y & Solar radiation, wind speed, and load. \\
\hline [18] & PV/WT/Hydro & Y & Diesel cost, PV capital, and replacement cost. \\
\hline [19] & PV/WT/BDG/Battery & $\mathrm{Y}$ & $\begin{array}{c}\text { Different parameters of the house, e.g., the area of } \\
\text { the house. }\end{array}$ \\
\hline [20] & PV/WT/Battery & $\mathrm{N}$ & None. \\
\hline [21] & PV/WT/BDG/Battery & $\mathrm{Y}$ & Cost of PV panel, wind turbine, as well as fossil fuel. \\
\hline [22] & PV/SDHW & $\mathrm{N}$ & None. \\
\hline
\end{tabular}

The consideration of generation units' aging effect and quantitative reliability assessment is considered to provide a robust system and more comprehensive information about generation systems for users' selection. A question arises naturally: how reliable will the NZEB be facing the failure and the degradation of the generation component?

The main contributions of the paper can be summarized in the following aspects: (1) an innovative reliability assessment approach is applied to evaluate the reliability of RES components in terms of the aging effect for the design of NZEB; (2) the impact of the number of years considered for net energy balance is firstly proposed and investigated, which can greatly affect the size or RES components and provide basic guidance for NZEB design principles; (3) the incorporation of the model that shows the relationship between mismatch ratio (the difference between energy demand and energy generation) and the probabilities of being NZEB is identified and updated considering both the main uncertainty parameters and generation system degradation.

\section{Problem Identification}

The current studies on NZEB are generally based on the assumption of ideal renewable energy generation, ignoring the impact of aging on the reliability of generation systems. In such cases, the obtained design option (C1) of RES has a lower probability to achieve the expected energy balance during the real application, as shown in Figure 2, where the y-axis indicates the probability to achieve net energy balance and the $x$-axis is the mismatch ratio. A simple consideration of the reliability assessment of RES is to give a constant availability value for them, which ignores the degradation of 
the generation system due to aging. Then, the obtained design option (C2) of RES may have a higher probability than that of design option $\mathrm{C} 1$, however, it is still lower than the expected value. A more accurate method is to consider the failures of generation systems, where the tendency of failure will increase concerning aging impact. In the third situation, a much larger size of generation systems (C3) may be required whilst it produces an accurate reliability assessment for generation adequacy. In this study, the effect of reliability of generation systems was identified and quantified on the target of net-zero energy balance design.

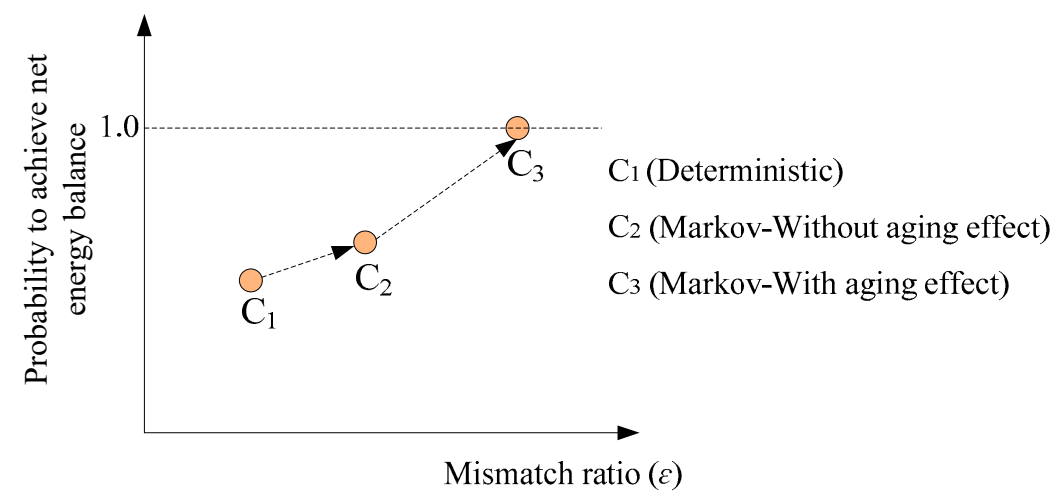

Figure 2. Design option of RES for NZEB under different cases.

Mismatch ratio $(\varepsilon)$ is an index used to identify the difference between on-site energy generation $\left(P_{g e n}\right)$ and building energy demand $\left(P_{d e m}\right)$ for the selected design system, and it can be calculated in the form as given in (1). The probability of being NZEB is an index that can be assessed by using the ratio between the number of satisfying years and the total years' simulation [14] as given in (2).

$$
\begin{gathered}
\varepsilon=\left(P_{\text {gen }}-P_{\text {dem }}\right) / P_{\text {dem }} \\
\text { Probability }=\frac{n^{\prime}}{n} \times 100 \%
\end{gathered}
$$

Optimal selection of RES for NZEB is conducted for 100 operation years, and a diagram of the design optimization procedure considering RES reliability with aging features is shown in Figure 3. In the first step, electricity generation models (i.e., RES models) and building energy consumption model (energy system models and cooling load model) were developed. By using a Markov chain, a reliability assessment of renewable energy systems in each year was conducted.

Subsequently, the profile of 100 years' parameters (e.g., solar radiation, wind velocity, cooling load, and building other load, etc.) was generated by the employment of Monte Carlo simulation in combination with the profile of a standard year. For each selected RES size, a mismatch ratio was calculated based on energy generation and energy consumption. The capacity of each RES combination needs to further identify whether it meets the evaluation criterion of NZEB (e.g., annual energy balance, 100-years energy balance). In the third step, the total cost (TC) and grid interaction index (GII) were obtained for those satisfied RES sizes. Exhaustive search approach is applied in this study for design optimization. In the last step, the optimal option of RES and the corresponding NZEB performance were sorted according to the normalized total $\operatorname{cost}\left(T C_{n}\right)$ or normalized grid interaction index $\left(G I I_{n}\right)$. 


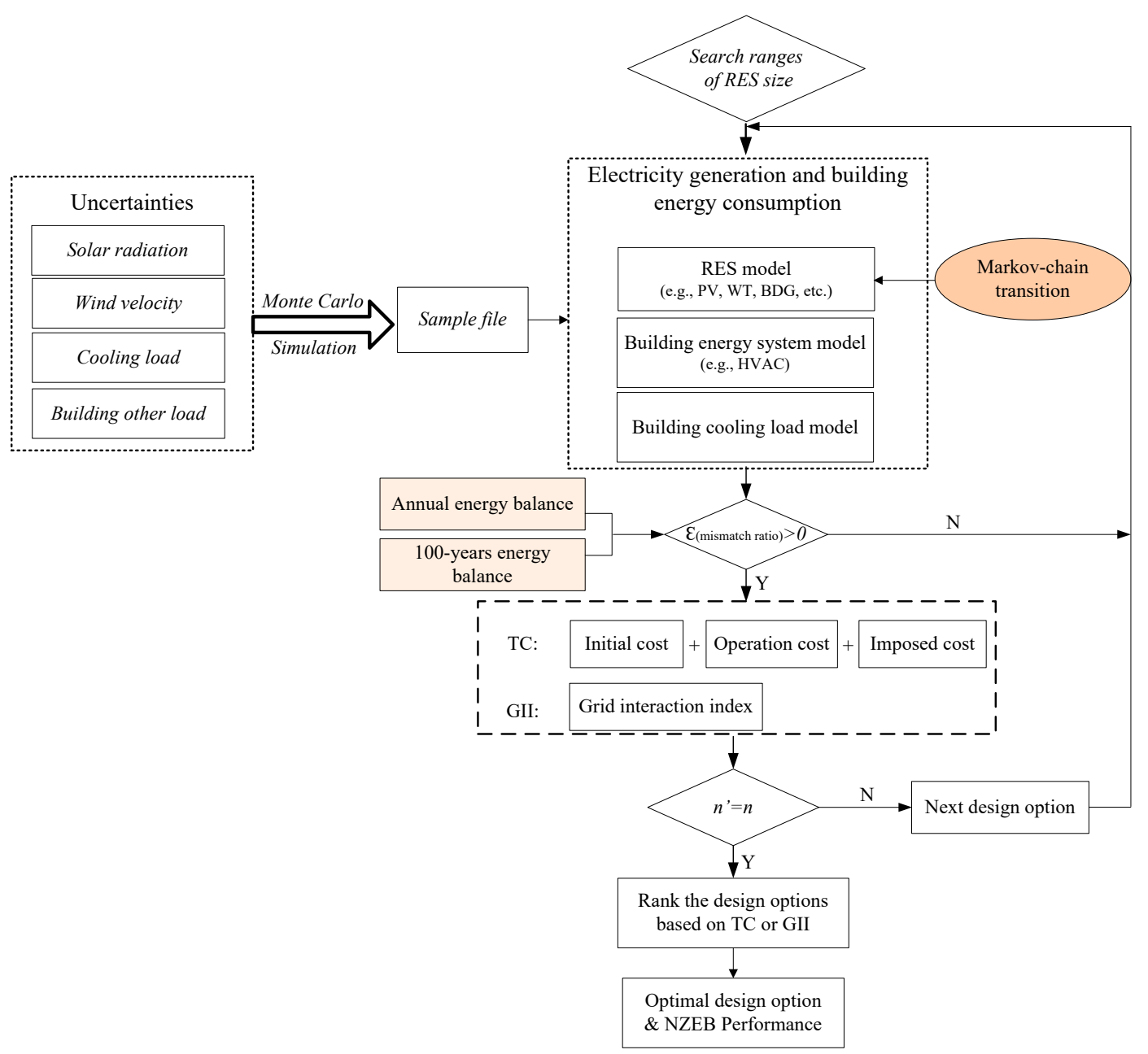

Figure 3. Diagram of design optimization for NZEB considering RES reliability. TC: total cost.

\section{System Generation Reliability Model}

The reliability modelling requires the implementation of Markov chains, which is defined as a representation of all possible states in a space state diagram [23]. Each state is connected between them by variables called transition rates. The states employed to define the reliability model of each generation unit are: " 1 " operating, "2" repairable failure, and " 3 " obsolescence. The transitions rates are defined as failure $\lambda_{r}$, repair $\mu_{r}$, and degradation $\lambda_{F}$ [24].

In this paper, Case 2 is considered to be an alternating renewal process with two states, as presented in Figure 4a. This model disregards the aging effect and brings inaccuracies in a realistic reliability model of the unit generation systems. Therefore, Case 3 is proposed which employs the model presented by Alvarez-Alvarado and Jayaweera [24]. The model contemplates the aging effect by adding a third state called obsolescence, which is an absorbing state, as presented in Figure $4 \mathrm{~b}$.

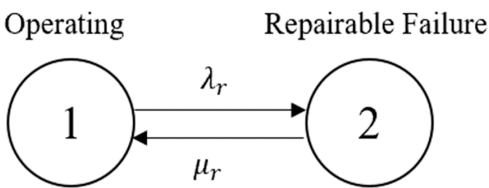

(a)

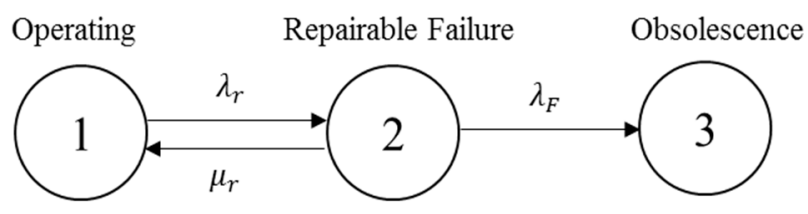

(b)

Figure 4. Markov chain model: (a) two states without the aging effect; (b) three states considering the aging effect. 
Later, the degradation rate can be obtained as a function of the $\lambda_{r}, \mu_{r}$, and the lifetime of the component $T_{W}$, that is [24]:

$$
\lambda_{F}=\frac{\lambda_{r}+\mu_{r}}{T_{W} \lambda_{r}-1}
$$

On the other hand, the probability of being in each state can be mathematically determined from the stochastic matrix of transition states $H$. This matrix is the infinitesimal generator of dimensions $z \times z$, where $z$ is the total number of states. The terms inside this matrix are defined as follows: $d_{i j}=\lambda_{i j}(i \neq j)$ and $d_{i i}=-\sum_{i \neq j} \lambda_{i j}$. Therefore, the $H$ matrices for the models presented in Figure $4 \mathrm{a}, \mathrm{b}$ are as shown in (4) and (5), respectively.

$$
\begin{gathered}
H_{\text {case } 2}=\left(\begin{array}{cc}
-\lambda_{r} & \lambda_{r} \\
\mu_{r} & -\mu_{r}
\end{array}\right) \\
H_{\text {case3 }}=\left(\begin{array}{ccc}
-\lambda_{r} & \lambda_{r} & 0 \\
\mu_{r} & -\mu_{r}-\lambda_{F} & \lambda_{F} \\
0 & 0 & 0
\end{array}\right)
\end{gathered}
$$

Then, the probability vector of all possible states is determined by (6), where $v$ is the eigenvalues of $H^{T}, v$ is the eigenvectors of $H^{T}$, and $k$ is a constant given by the initial state; $T$ indicates the transpose of the matrix $[25,26]$.

$$
P(t)=\sum_{i=1}^{z} k_{i} v e^{-\chi_{i} t}
$$

Applying this criterion given in (4) and (5), the probabilities of being in each state are as presented in (7) and (8), respectively.

where :

$$
\text { case } 2:\left\{\begin{array}{l}
P_{1}=k_{1} v_{11} e^{-\chi_{1} t}+k_{2} v_{12} e^{-\chi_{2} t} \\
P_{2}=k_{1} v_{21} e^{-\chi_{1} t}+k_{2} v_{22} e^{-\chi_{2} t}
\end{array}\right.
$$

where :

$k_{1}=\frac{\lambda_{r}}{\lambda_{r}+\mu_{r}} ; k_{2}=-\frac{\lambda_{r}}{\lambda_{r}+\mu_{r}} ; \chi_{1}=0 ; \chi_{2}=-\lambda_{r}-\mu_{r} ; v_{11}=\frac{\mu_{r}}{\lambda_{r}} ; v_{12}=-1 ; v_{21}=1 ; v_{22}=1$

$$
\text { case 3: }\left\{\begin{array}{l}
P_{1}=k_{1} v_{11} e^{-\chi_{1} t}+k_{2} v_{12} e^{-\chi_{2} t}+k_{3} v_{13} e^{-\chi_{3} t} \\
P_{2}=k_{1} v_{21} e^{-\chi_{1} t}+k_{2} v_{22} e^{-\chi_{2} t}+k_{3} v_{23} e^{-\chi_{3} t} \\
P_{3}=k_{1} v_{31} e^{-\chi_{1} t}+k_{2} v_{32} e^{-\chi_{2} t}+k_{3} v_{33} e^{-\chi_{3} t}
\end{array}\right.
$$

$$
\begin{aligned}
& k_{1}=1 ; k_{2}=\frac{\lambda_{r}+\lambda_{F}+\mu_{r}-a}{2 a} ; k_{3}=\frac{-\lambda_{r}-\lambda_{F}-\mu_{r}-a}{2 a} ; a=\sqrt{-4 \lambda_{r} \lambda_{F}+\left(\lambda_{r}+\lambda_{F}+\mu_{r}\right)^{2}} \\
& \chi_{1}=0 ; \chi_{2}=\frac{-\lambda_{r}-\mu_{r}-\lambda_{F}-a}{2} ; \chi_{3}=\frac{-\lambda_{r}-\mu_{r}-\lambda_{F}+a}{2} \\
& v_{11}=0 ; v_{12}=\frac{\left(\lambda_{r}-\mu_{r}-\lambda_{F}+a\right)\left(\lambda_{2}+\mu_{r}+\lambda_{F}+a\right)}{4 \lambda_{r} r_{F}-\lambda_{r}-\lambda_{F}+a} ; v_{13}=\frac{\left(\lambda_{r}-\mu_{r}-\lambda_{F}-a\right)\left(\lambda_{r}+\mu_{r}+\lambda_{F}-a\right)}{4 \lambda_{r} \lambda_{F}} ; v_{21}=0 \\
& v_{22}=\frac{-\lambda_{r}-\mu_{r}-\lambda_{F}-a}{2 \lambda_{F}} ; v_{23}=\frac{-\lambda_{r}-\mu_{r} \lambda_{F}+a}{2 \lambda_{F}} ; v_{31}=1 ; v_{32}=1 ; v_{33}=1
\end{aligned}
$$

A measure of reliability is the availability of the component, and it is defined as the sum of the probabilities of being in the operating state. For the models given in Figure $4 a, b$, there is just the operating state (state " 1 "), therefore, their availability is defined as presented in (9) and (10), respectively.

$$
\begin{gathered}
\text { Case 2: } A(t)=k_{1} v_{11} e^{-v_{1} t}+k_{2} v_{12} e^{-v_{2} t} \\
\text { Case 3: } A(t)=k_{1} v_{11} e^{-v_{1} t}+k_{2} v_{12} e^{-v_{2} t}+k_{3} v_{13} e^{-v_{3} t}
\end{gathered}
$$

Then, considering the reliability data of PV, WT, and BDG listed in Table 2 and following the procedure stated above, the availability for each generation system is obtained as shown in Figure 5 . In addition, Table 3 provides the availability ranges for the generation systems for each case study. 
Table 2. Reliability data of PV, WT, and BDG [27].

\begin{tabular}{cccc}
\hline Generation & $\lambda_{r}[1 / \mathrm{yr}]$ & $\mu_{r}[1 / \mathrm{yr}]$ & $T_{W}$ (Year) \\
\hline PV & 3 & 90 & 25 \\
WT & 4.6 & 80 & 25 \\
BDG & 9.2 & 50 & 25 \\
\hline
\end{tabular}

Table 3. Availability ranges for PV, WT, and BDG.

\begin{tabular}{|c|c|c|c|}
\hline \multirow{2}{*}{ Generation } & \multicolumn{3}{|c|}{ Availability } \\
\hline & Case 1 & Case 2 & Case 3 \\
\hline PV & 1.00 & 0.97 & $0.42-0.94$ \\
\hline WT & 1.00 & 0.96 & $0.41-0.93$ \\
\hline BDG & 1.00 & 0.95 & $0.41-0.92$ \\
\hline
\end{tabular}

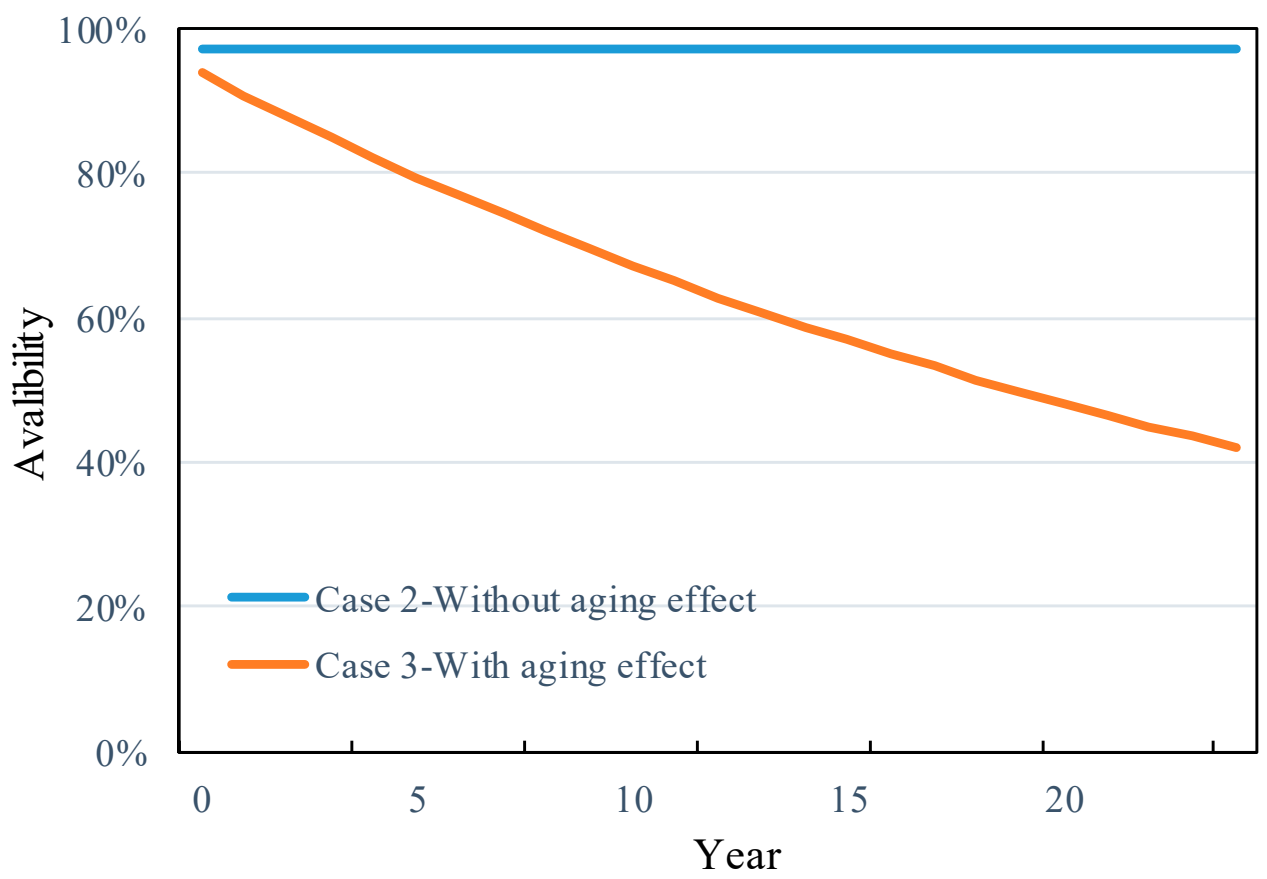

Figure 5. The effect of operation year on availability.

It is clear from Table 3 that without consideration of the aging factor, the reliability of the RES does not vary significantly. However, the availability shows a significant variation ranging from 0.40 to 0.95 for generation units.

\section{Evaluation Indicator}

In this study, the total cost of NZEB comprises of the initial cost (i.e., investment of RES), operation cost (i.e., electricity cost from the grid and the cost of biodiesel) during the building application stage, and the imposed cost (i.e., an additional investment cost due to reliability consideration). This is given in (11).

$$
T C=I C+O C+A C
$$

Grid interaction index (GII) is an indicator representing the average stress of a building on the power grid, and it is defined as the standard deviation of the building-grid interaction over the period 
as formed in (12). The building-grid interaction is calculated based on the ratio between net exported energy and the average energy demand in the building during a given period, as shown in (13).

$$
\begin{gathered}
G I I=\operatorname{STD}\left(f_{\text {grid }, \mathrm{i}, \mathrm{T}}^{\prime}\right) \\
\mathrm{f}_{\text {grid }, \mathrm{i}, \mathrm{T}}^{\prime}=\frac{\mathrm{P}_{\mathrm{ex}, \mathrm{i}}-\mathrm{P}_{\mathrm{im}, \mathrm{i}}}{\int_{\mathrm{t} 1}^{\mathrm{t} 2} \mathrm{P}_{\mathrm{dem}, \mathrm{i}} \mathrm{dt} / \mathrm{T}}
\end{gathered}
$$

The objective in this study was to minimize the total cost or grid interaction index from the selected ranges of RES for NZEB, as indicated in (14), where $T C_{n}, G I I_{n}$, and X are the normalized total cost, normalized grid interaction index, and the decision variables on the selected combination sizes of each generation unit, respectively. In order to achieve the target of net-zero energy building, the selected size of each generation unit should be within the set size ranges (15), the amount of energy generation during certain periods should be larger than or equal to the building energy demand (16), and the energy/cooling balance must be met in each hour (17). As shown in Figure 3, the exhaustive searching method will be applied to solve the optimization.

$$
\text { Objective function : } f=T C_{n} \text { or } G I I_{n}
$$

Subject to

$$
\begin{aligned}
& A X \leq a \\
& \mathrm{~g}_{1} X \leq 0 \\
& \mathrm{~g}_{2} X=0
\end{aligned}
$$

\section{Building Features}

The first zero-carbon building (ZCB) in Hong Kong, China, was used to identify the effect of reliability of RES on design option and corresponding performance. This is a three-story building (area $=1520 \mathrm{~m}^{2}$ ) with the air-conditioned area of approximately $990 \mathrm{~m}^{2}$. Two types of generation systems, i.e., photovoltaic (PV) of $1015 \mathrm{~m}^{2}$ and a biodiesel generator (BDG) with a rated power of $100 \mathrm{~kW}$, are employed to provide energy for the grid-connected building. In this study, the wind turbine (WT) system was also assumed to be one of the potential generation systems, in addition to PV and BDG. The cooling load of the building was undertaken by three electric chillers, one absorption chiller driven by BDG, and the peak cooling load was about $163 \mathrm{~kW}$. A schematic diagram of the energy systems in the studied building is shown in Figure 6.

The main key parameters for the energy system are listed in Table 4. The total number of PV, WT, and BDG size combination was 945 (Table 4: $21 \times 9 \times 5=945$ ), and the lifetime of the three systems was set to be 25 years.

Four uncertain parameters, i.e., solar radiation, wind velocity, cooling load, and building other load (electricity usage, except for cooling load), were considered to be varying over a 100-years, and it was assumed that they follow uniform distributions. It was assumed that when the component reaches the obsolescence state (end lifetime), this is immediately replaced and the lifecycle starts again. The study was conducted for the next 100-years simulation to investigate the impact of uncertainty from energy demand, and energy generation can also be reflected.

Table 4. Information on the design optimization of RES.

\begin{tabular}{ccc}
\hline Items & Parameters & Conditions \\
\hline & $\mathrm{WT}[\mathrm{kW}]$ & $0: 20: 160$ \\
Design variables & $\mathrm{BDG}[\mathrm{kW}]$ & $20: 20: 100$ \\
& $\mathrm{PV}\left[\mathrm{m}^{2}\right]$ & $0: 200: 4000$ \\
\hline
\end{tabular}


Table 4. Cont.

\begin{tabular}{ccc}
\hline Items & Parameters & Conditions \\
\hline & Heat recovery system efficiency [\%] & 80 \\
Biodiesel generator efficiency [\%] & 30 \\
Chiller coefficient of absorption [\%] & 70 \\
Energy system & 25 \\
& Lifetime for biodiesel generator [year] & 25 \\
Lifetime for photovoltaic [year] & 25 \\
Lifetime for wind turbine [year] & $70 \times 3$ \\
Rated power of electric chillers [kW] & $70 \times 1$ \\
Rated power of absorption chillers [kW] & 205.53 \\
Price & Unit price of biodiesel generator [USD/kW] & 378.17 \\
& Unit price for photovoltaic [USD/m $\left.{ }^{2}\right]$ & 714.29 \\
Unit price for wind turbine [USD/kW] & 1.3 \\
Oil price [USD/l] & $0.13 / 0.065$ \\
\hline Delivered/Exported price [USD $/ \mathrm{kWh}]$ & Uniform $\left(\delta_{I}= \pm 0.2\right)$ \\
\hline Uncertain parameters & Solar radiation $\left(I_{\text {irra }}\right)$ & Uniform $\left(\delta_{\text {wind }}= \pm 0.1\right)$ \\
& Wind velocity $\left(v_{\text {wind }}\right)$ & Uniform $\left(\delta_{Q}= \pm 0.3\right)$ \\
& Cooling load $\left(Q_{c}\right)$ & Uniform $\left(\delta_{O t h}= \pm 0.15\right)$ \\
\hline
\end{tabular}

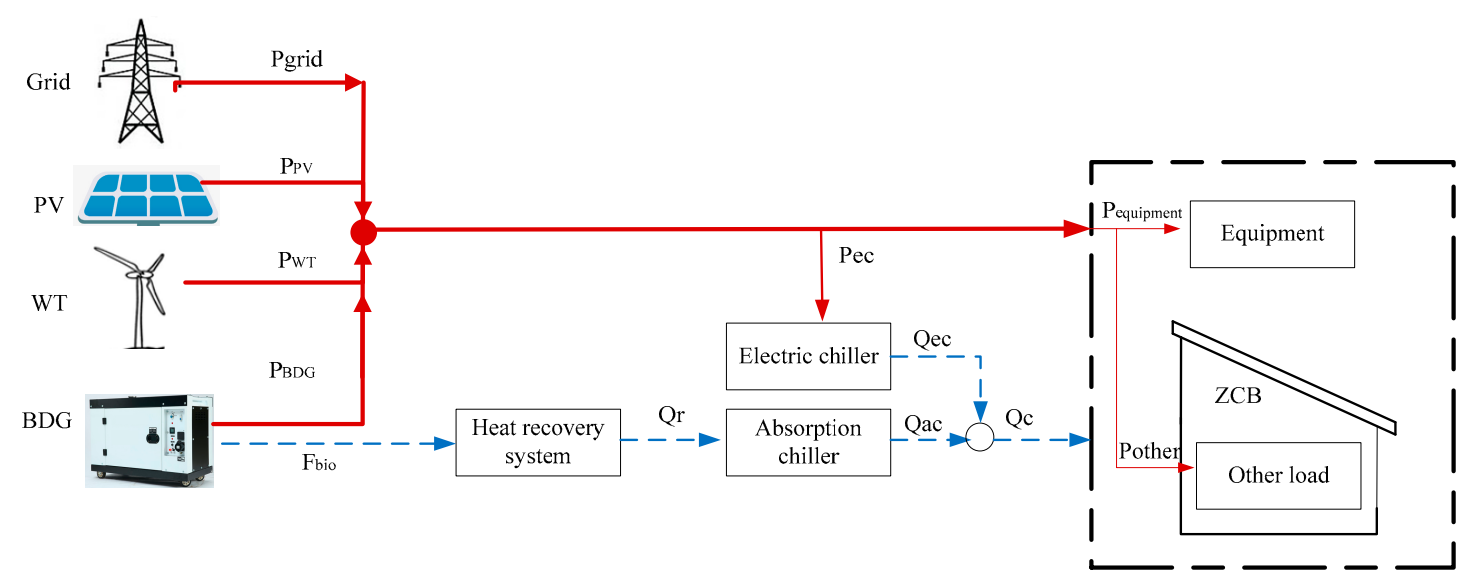

Figure 6. Energy flow relationship among the energy systems $[7,11,14]$.

The cooling system of the building is provided by three electric and one absorption chiller, as shown in (18). The absorption chiller $\left(Q_{a c}\right)$ is driven by BDG and is given priority to handle the cooling load, whereas the rest of the cooling load is undertaken by the electric chillers $\left(Q_{e c}\right)$, as shown in (19) and (20).

$$
\begin{gathered}
Q_{c}=Q_{e c}+Q_{a c} \\
Q_{a c}=Q_{c} \mid Q_{c}<Q_{a c, d e s i g n} \\
Q_{a c}=\left.Q_{a c, \text { design }}\right|_{Q_{c}>Q_{a c, d e s i g n}}
\end{gathered}
$$

The total electricity consumption of the building $\left(P_{d e m}\right)$ consists of five parts, as shown in (21), where $\mathrm{P}_{\mathrm{ec}}$ is the power consumed by electric chillers, $\mathrm{P}_{\text {pump }}$ is the power consumed by cooling water pumps and chiller water pumps, $P_{c t}$ is the power consumed by cooling tower fans, $P_{f a n}$ is the power consumed by AHU (air handling unit) fans, and $\mathrm{P}_{\text {other }}$ is the power consumed by other appliances, such as lighting and socket outlet. The power supply system consists of on-site RES (i.e., PV, WT, and BDG) and the grid, as shown in (22). The hourly electricity consumption in the building should be equal to the amount of supplied power by the sources given in (22). It is noted that heating load 
does not exist for the building in Hong Kong since Hong Kong belongs to the hot summer and warm winter zone.

$$
\begin{gathered}
P_{\text {dem }}^{t}=P_{\text {ec }}^{t}+P_{\text {pump }}^{t}+P_{c t}^{t}+P_{\text {fan }}^{t}+P_{\text {other }}^{t} \\
P_{\text {supply }}^{t}=P_{P V}^{t}+P_{W T}^{t}+P_{B D G}^{t}+P_{\text {grid }}^{t}
\end{gathered}
$$

Electricity consumption of the electric chillers $\left(P_{e c}\right)$, pumps models $\left(P_{\text {pump }}\right)$, cooling tower $\left(P_{c t}\right)$, and AHU fan $\left(P_{f a n}\right)$ can be modelled in the following form, based on the empirical model and the on-site data in ZCB [7]:

$$
\begin{gathered}
P_{e c}=Q_{e c} / C O P_{e c} \\
P_{c w p}=\left(\frac{10 m_{w}}{m_{w, \text { design }}}-1\right)\left(\frac{m_{w}}{m_{w, \text { design }}}\right)^{2} \\
P_{c t}=P_{c t, \text { design }}\left(\frac{Q_{c t}}{Q_{c t, \text { design }}}\right)^{1.5} \\
P_{\text {fan }}=\frac{8 v_{a}}{v_{a, \text { design }}}+12\left(\frac{v_{a}}{v_{a, \text { design }}}\right)^{3}
\end{gathered}
$$

Energy generation in a PV system, WT system, and BDG system can be evaluated by using (27), (28), and (29), respectively. The power generation of BDG depends on the building cooling demand (26) since it is controlled following the cooling load. Furthermore, fuel consumption of BDG $\left(F_{b i o}\right)$ during the operation stage can be assessed by (30).

$$
\begin{gathered}
P_{P V}=A_{d e s} \eta_{m} P_{f} \eta_{P C} I_{\text {irra }} \\
P_{W T}=0.5 \rho_{a} A_{W T} v_{\text {wind }}^{3} c_{p, w} \eta_{W T} \\
P_{B D G}=Q_{r} \eta_{B D G} /\left(\left(1-\eta_{B D G}\right) \eta_{h r s}\right) \\
F_{b i o}=A_{G} P_{B D G}+B_{G} P_{\text {rated }, B D G}
\end{gathered}
$$

\section{Results and Discussion}

RES design was optimized for all three cases. The effect of reliability of generation systems can be identified by comparing the results of the three cases. The required RES size in Case 3, when the aging effect is considered, was expected to be larger than that in the other two cases. Furthermore, the number of years concerned for net energy balance evaluation may have a great impact on system selection and NZEB performance since the degeneration of RES due to the aging effect was considered. Therefore, both scenarios are investigated in the following section.

\subsection{Performance Evaluation: Annual Energy Balance}

In terms of the annual energy balance, the optimal design results based on a 100-years simulation are presented in Table 5. It was found that the optimal sizes for Case 3 were much larger than that for the ones in Case 1 and Case 2; for example, the combination of optimal RES consisted of WT of $160 \mathrm{~kW}$, BDG of $20 \mathrm{~kW}$, and PV of $200 \mathrm{~m}^{2}$ in Case 1, whilst the PV size increased to be $400 \mathrm{~m}^{2}$ in Case 2, and it increased to be $3,600 \mathrm{~m}^{2}$ in Case 3 . The main reason was that a slight reduction of availability was found in each generation unit (it was more than 0.95) in Case 2, whilst a large variation range of availability (between 0.4 and 0.95 ) was seen in Case 3, as shown in Table 3. In addition, the total cost $\left(T_{C n}\right)$ and grid interaction index $\left(G I I_{n}\right)$ in Case 3 were identified to be two times and three times, respectively, that of Case 1.

In order to have a better understanding of actual NZEB performance under the selected RES sizes in each year, a comparison of annual energy generation and annual mismatch ratio for the optimal options in the three cases is presented in Figure 7 (for $T_{C n}$ ) and Figure 8 (for $G I I_{n}$ ), respectively. 
In terms of the total cost, the average values of annual energy generation and annual mismatch ratio were $209,775 \mathrm{kWh}$ and $-8.2 \%$ (Case 1), 223,214 $\mathrm{kWh}$ and $-2.3 \%$ (Case 2), and 438,226 kWh and 91.9\% (Case 3), respectively.

Table 5. Optimal size and performance for NZEB.

\begin{tabular}{ccccccc}
\hline Case & $\begin{array}{c}\text { Indicator } \\
\text { (Objective) }\end{array}$ & $\begin{array}{c}\mathbf{W T} \\
\mathbf{( k W )}\end{array}$ & $\begin{array}{c}\text { BDG } \\
\mathbf{( \mathbf { k W } )}\end{array}$ & $\begin{array}{c}\mathbf{P V} \\
\mathbf{( \mathbf { m } ^ { 2 } )}\end{array}$ & $\begin{array}{c}\mathbf{F} \\
{[-\mathbf{]}}\end{array}$ & $\begin{array}{c}\varepsilon \\
{[\mathbf{\%}]}\end{array}$ \\
\hline \multirow{2}{*}{ 1: Deterministic } & $T_{C n}$ & 160 & 20 & 200 & 0.71 & 46.4 \\
\cline { 2 - 7 } & $G I_{n}$ & 40 & 60 & 800 & 0.76 & 32.5 \\
\hline \multirow{2}{*}{ 2: Markov-No aging effect } & $T_{C n}$ & 160 & 20 & 400 & 0.74 & 49.1 \\
\cline { 2 - 7 } & $G I I_{n}$ & 40 & 80 & 400 & 0.77 & 22.8 \\
\hline \multirow{2}{*}{ 3: Markov-aging effect } & $T_{C n}$ & 160 & 20 & 3600 & 1.52 & 91.2 \\
\cline { 2 - 7 } & $G I_{n}$ & 160 & 80 & 2200 & 2.37 & 96.2 \\
\hline
\end{tabular}

In terms of the grid interaction index, the average values of annual energy generation and annual mismatch ratio were 170,034 kWh and $-20.3 \%$ (Case 1), 160,107 kWh and $-23.1 \%$ (Case 2), and $407,702 \mathrm{kWh}$ and $96.2 \%$ (Case 3), respectively. Meanwhile, the fluctuation of both parameters showed approximately periodic variations.

(a)

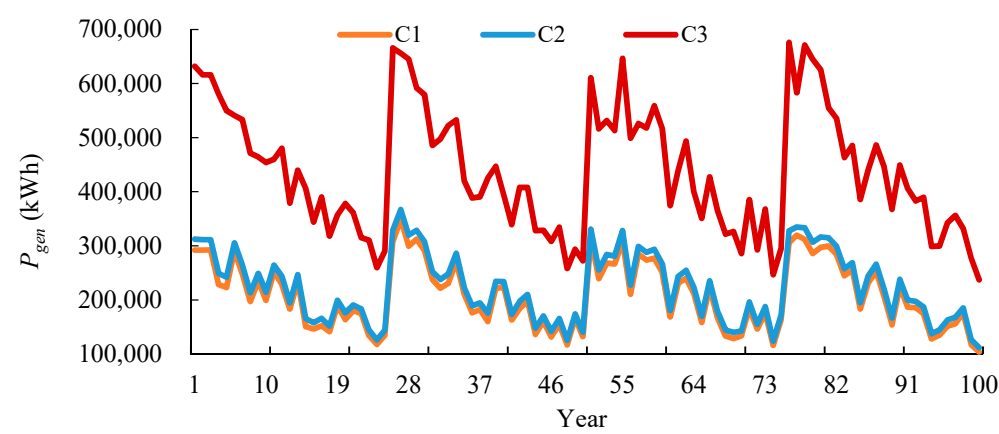

(b)

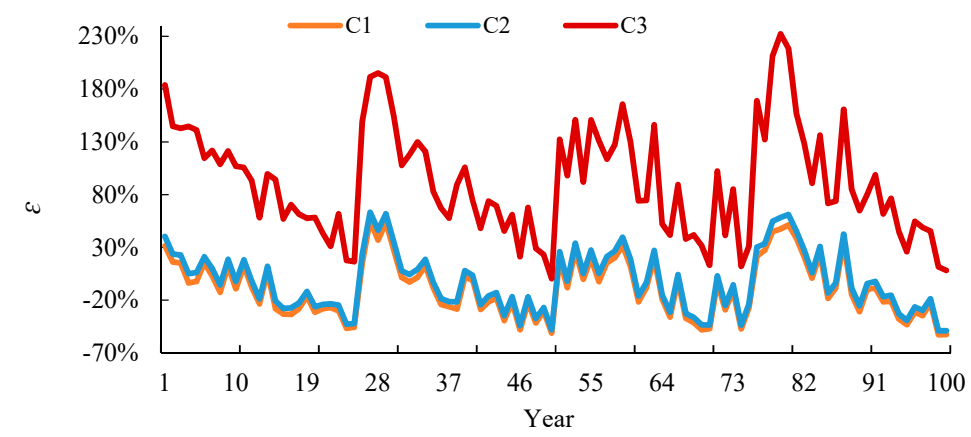

Figure 7. Annual performance of NZEB under optimal options with the aging effect (considering $T C_{n}$ ): (a) Annual energy generation; (b) Annual mismatch ratio. 
(a)

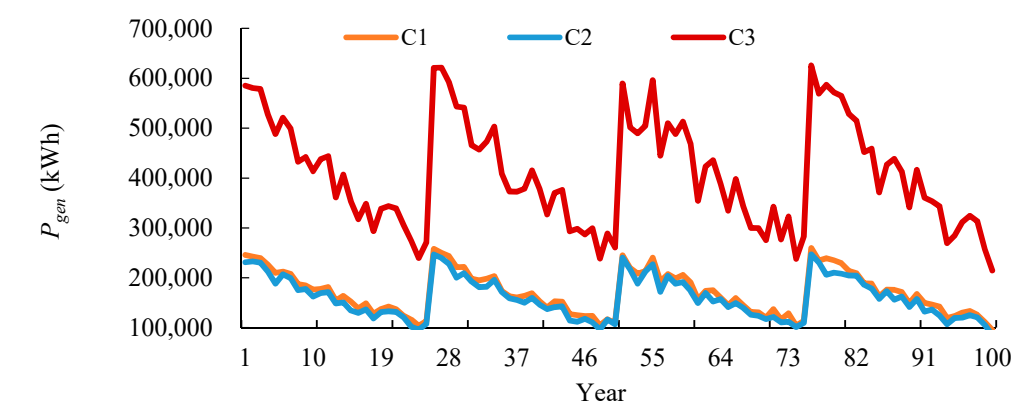

(b)

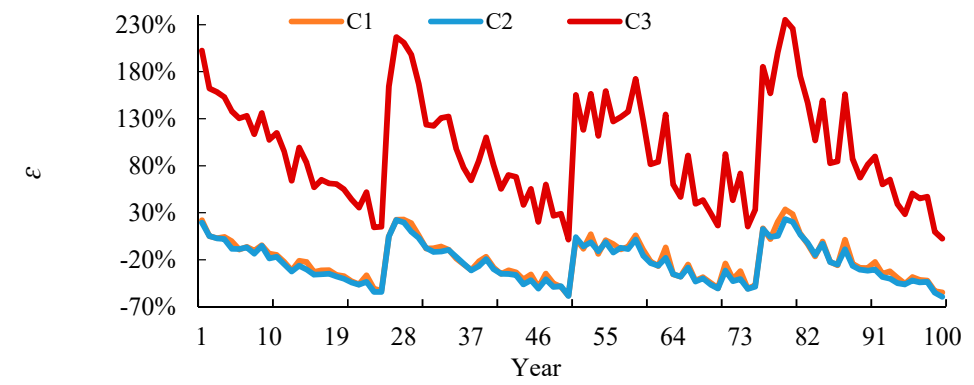

Figure 8. Annual performance of NZEB under optimal options with the aging effect (considering GIIn):

(a) Annual energy generation; (b) Annual mismatch ratio.

Figures 9 and 10 further present the average annual energy generation of the selected option and the corresponding probability to be NZEB when the aging effect is taken into consideration. It can be seen that the average annual energy generation was less than its energy consumption in Case 1 and Case 2, whilst it was about two times that of energy consumption in Case 3. It was also interesting to find that the probability to be NZEB during practical application was only 0.35 for Case 1 and 0.43 for Case 2 when the total cost was considered, while it was 0.2 for Case 1 and 0.17 for Case 2 when the grid interaction index was considered. Thus, the aging effect had a significant impact on system selection and expected target.

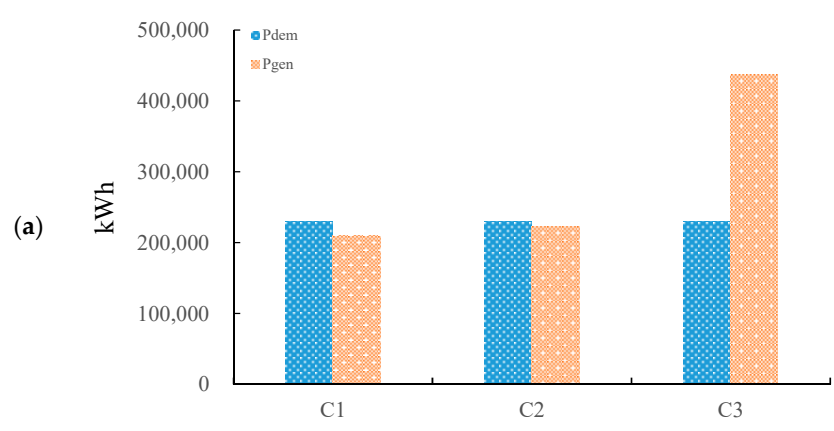

(b)

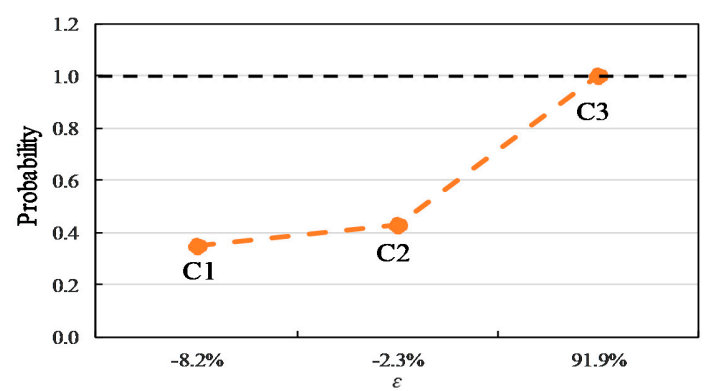

Figure 9. Average performance of NZEB under optimal options with the aging effect (considering $T C_{n}$ ): (a) Annual energy generation; (b) Probability of being NZEB. 
(a)

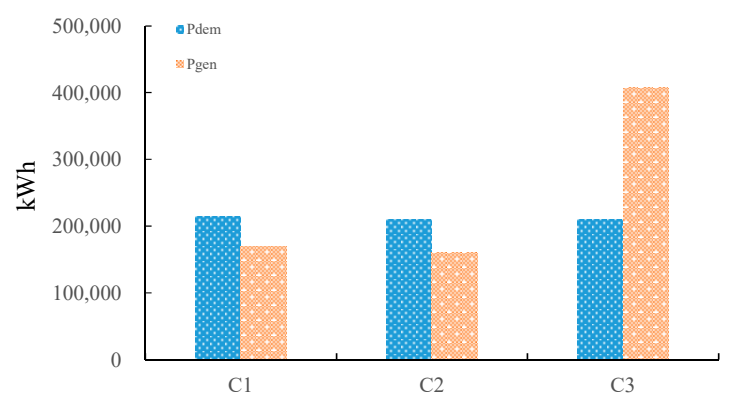

(b)

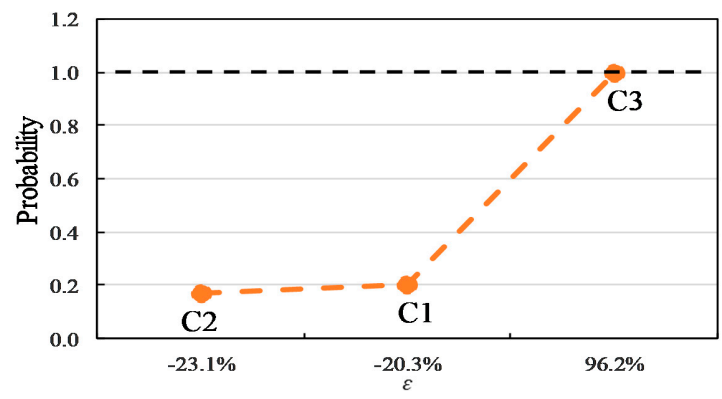

Figure 10. Average performance of NZEB under optimal options with the aging effect (considering $G_{n}$ ): (a) Annual energy generation; (b) Probability of being NZEB.

\subsection{Performance Evaluation: 100-Years Energy Balance}

In terms of the 100-years energy balance, the optimal design results are presented in Table 6. For the total cost, the selected options in Case 3 were larger than those in Case 1 and Case 2, but it was reduced from $3600 \mathrm{~m}^{2}$ under annual year balance concerned (Table 5) to $600 \mathrm{~m}^{2}$ under 100-years energy balance. The total cost did not show much reduction in Case 1 and Case 2, however, in Case 3 , compared to the annual year balance, the cost was reduced to half. In addition, a remarkable reduction from $92 \%$ to $3 \%$ was seen in the mismatch ratio in Case 3, indicating a much smaller size was required for the 100-years energy balance. A similar tendency was found for the performance of the grid interaction index. A further comparison of annual energy generation and annual mismatch ratio in the three cases under 100-years energy balance is presented, when the aging effect was taken into consideration, in Figure 11 (regarding $T C_{n}$ ) and Figure 12 (regarding $G I_{n}$ ).

Table 6. Optimal size and performance for NZEB.

\begin{tabular}{ccccccc}
\hline \multirow{2}{*}{ Case } & $\begin{array}{c}\text { Indicator } \\
\text { (Objective) }\end{array}$ & $\begin{array}{c}\mathbf{W T} \\
\mathbf{( k W )}\end{array}$ & $\begin{array}{c}\text { BDG } \\
\mathbf{( k W )}\end{array}$ & $\begin{array}{c}\mathbf{P V} \\
\mathbf{( \mathbf { m } ^ { 2 } )}\end{array}$ & $\begin{array}{c}\mathbf{F} \\
{[-\mathbf{-}}\end{array}$ & $\begin{array}{c}\varepsilon \\
{[\mathbf{\%}]}\end{array}$ \\
\hline \multirow{2}{*}{ 1: Deterministic } & $T_{C n}$ & 160 & 20 & 0 & 0.69 & 36.0 \\
\cline { 2 - 7 } & $G I_{n}$ & 40 & 60 & 200 & 0.57 & 0.52 \\
\hline \multirow{2}{*}{ 2: Markov-No aging effect } & $T_{C n}$ & 160 & 20 & 0 & 0.69 & 29.9 \\
\cline { 2 - 7 } & $G I_{n}$ & 40 & 60 & 400 & 0.60 & 5.05 \\
\hline \multirow{2}{*}{ 3: Markov-aging effect } & $T_{C n}$ & 160 & 20 & 600 & 0.78 & 3.05 \\
\cline { 2 - 7 } & $G I_{n}$ & 60 & 60 & 1200 & 1.03 & 1.34 \\
\hline
\end{tabular}

In terms of the total cost, the average values of annual energy generation and annual mismatch ratio were 196,337 $\mathrm{kWh}$ and $-14.1 \%$ (Case 1), 196,377 $\mathrm{kWh}$ and $-14.1 \%$ (Case 2), and 236,652 kWh and $3.6 \%$ (Case 3), respectively. In terms of the grid interaction index, the average values of annual energy generation and annual mismatch ratio were $129,719 \mathrm{kWh}$ and $-39.3 \%$ (Case 1), 143,157 kWh and $-33.0 \%$ (Case 2), and 218,019 kWh and 2.2\% (Case 3), respectively. Following a similar pattern of the annual energy balance, the fluctuations of both parameters showed approximately periodic variations. 
(a)

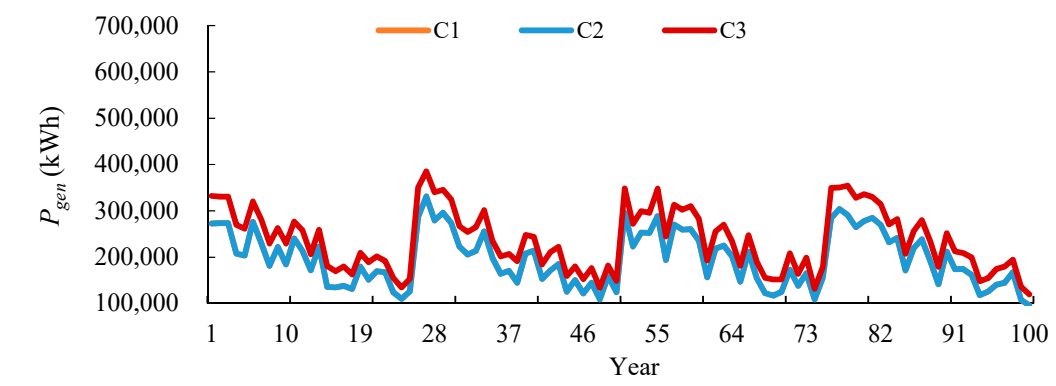

(b)

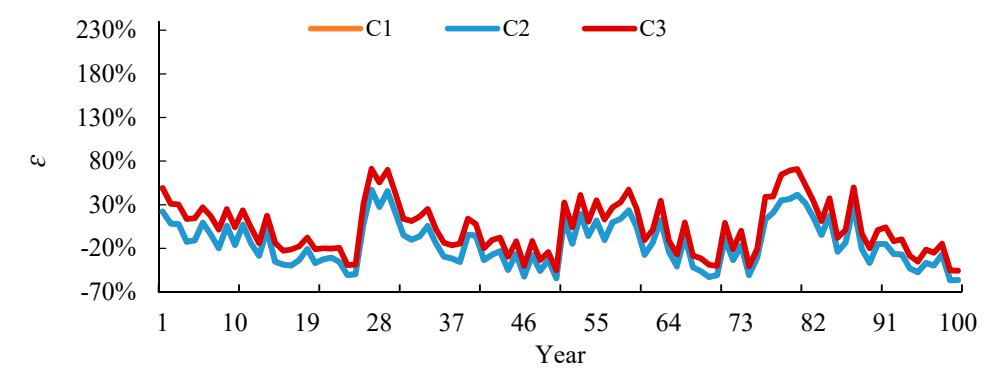

Figure 11. Annual performance of NZEB under optimal options with the aging effect (considering $T C_{n}$ ): (a) Annual energy generation; (b) Annual mismatch ratio.

The average annual energy generation of the selected option and the corresponding probability to be NZEB in the three cases were further compared when the aging effect was taken into consideration, as shown in Figures 13 and 14. Different from that under annual energy balance criteria, the required annual energy generation in Case 3 was much less than that in Case 1 and Case 2.

In terms of the total cost, the probability to be NZEB in Case $1(0.3)$ was the same as that in Case 2 since they had the same design option, whilst it was about 0.5 in Case 3 during practical application. In terms of the grid interaction index, the probability to be NZEB during practical application was only $0.0,0.06$, and 0.46 for Case 1, Case 2, and Case 3, respectively. Thus, the number of years for net energy balance evaluation also had a significant impact on system selection and expected target.

(a)

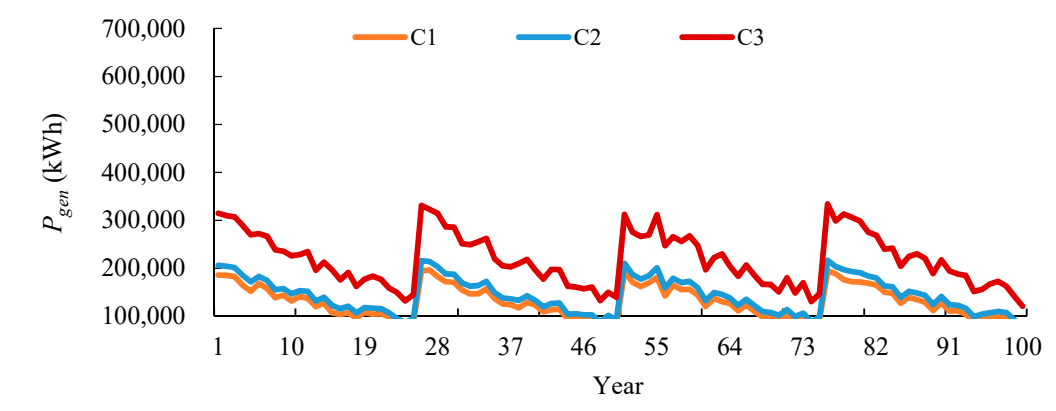

(b)

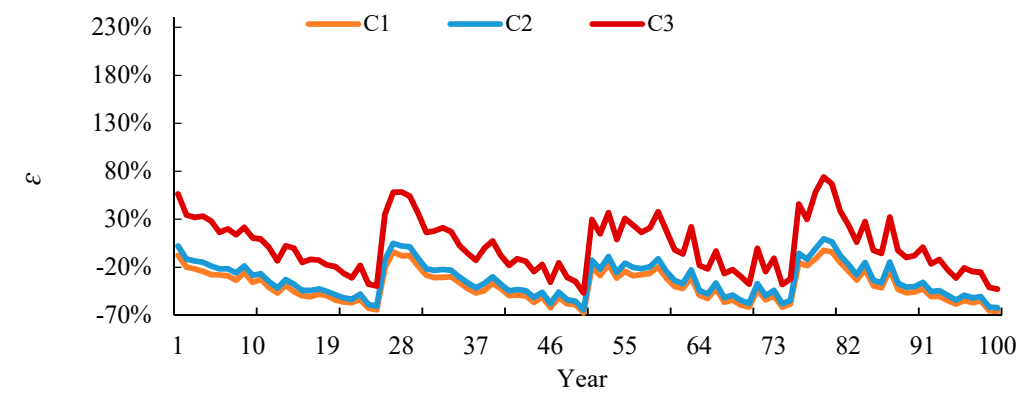

Figure 12. Annual performance of NZEB under optimal options with the aging effect (considering $G I I_{n}$ ): (a) Annual energy generation; (b) Annual mismatch ratio. 


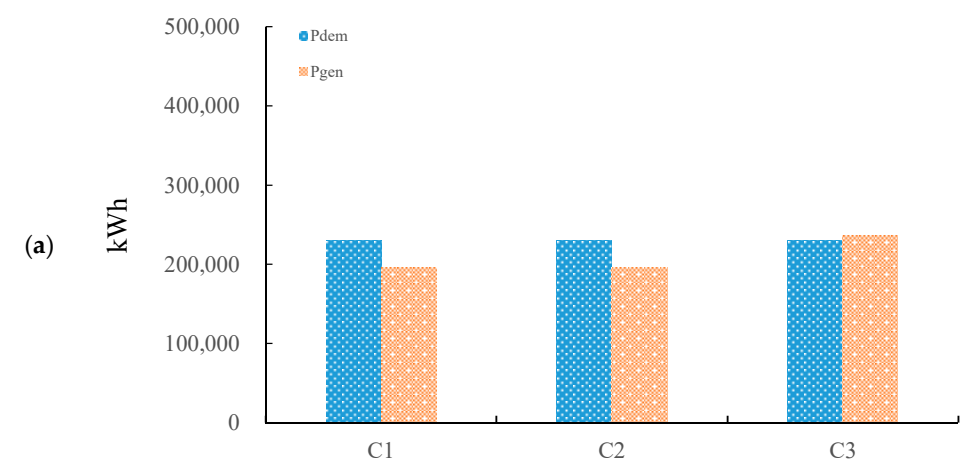

(b)

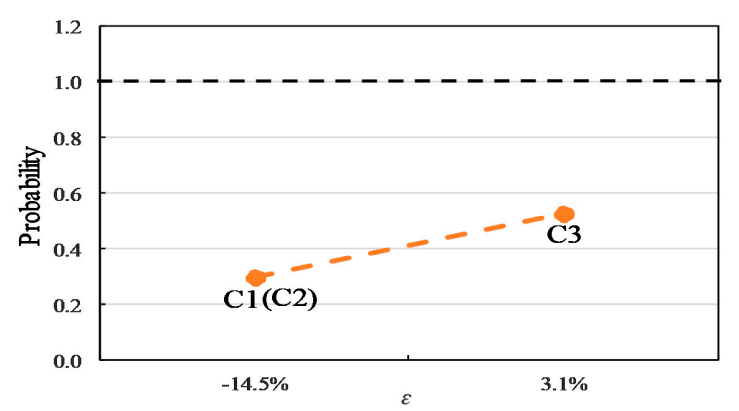

Figure 13. Average performance of NZEB under optimal options with the aging effect (considering $T C_{n}$ ): (a) Average annual energy generation; (b) Probability of being NZEB.

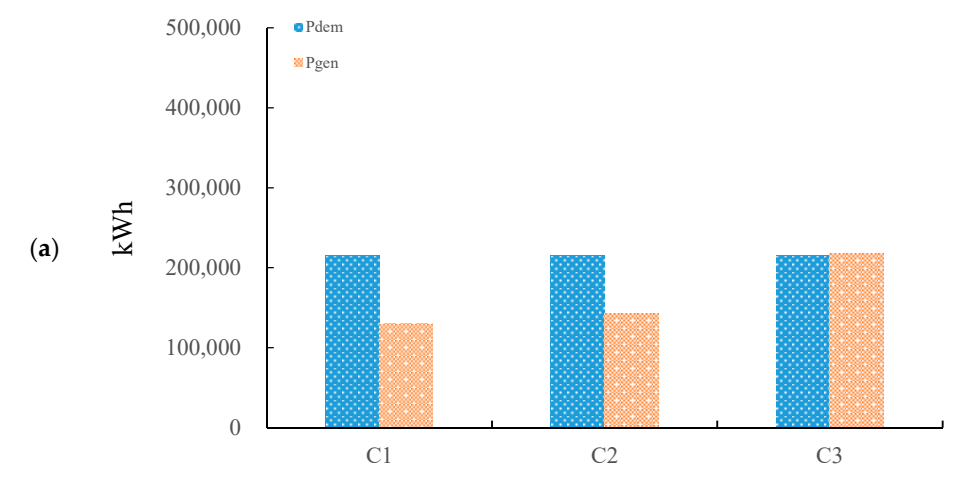

(b)

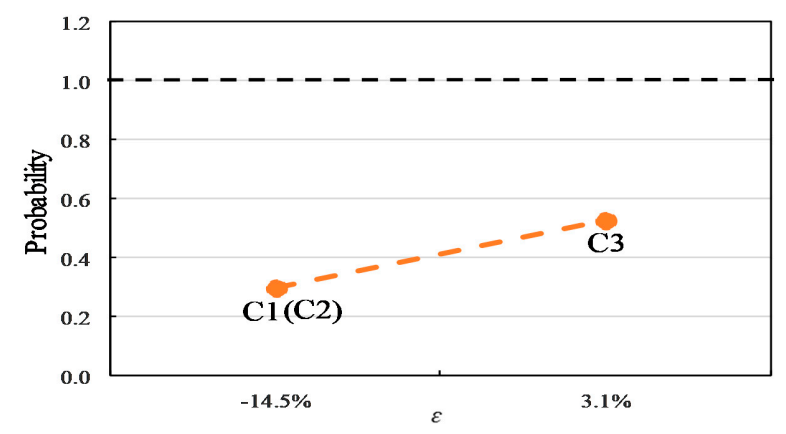

Figure 14. Average performance of NZEB under optimal options with the aging effect (considering GIIn): (a) Average annual energy generation; (b) Probability of being NZEB.

\subsection{Relationship between Probabilities and Mismatch Ratio}

The mismatch ratio of the selected design option has a significant impact on the probability of being NZEB, as indicated in [8] and [12]. Therefore, the selected mismatch ratio can reflect its ability on the NZEB level achieved, which can provide a general perspective for designers. All of the size combinations (945) were investigated in a 100-years operation, and it was interesting to obtain three 
fitting formulas for the studied three cases, as shown in Figure 15. The coefficients of determination $\mathrm{R}^{2}$ of the three fitting formula were all above 0.98 , indicating a good relationship between the mismatch ratio and the probabilities.

Case 1: $y_{1}=36.914 x^{5}-0.8983 x^{4}-16.554 x^{3}+0.3929 x^{2}+2.9041 x+0.4636 ;-0.5<x<0.5\left(R^{2}=0.988\right)$;

Case 2: $y_{2}=37.906 x^{5}-1.9154 x^{4}-16.716 x^{3}+0.6118 x^{2}+2.9024 x+0.4563 ;-0.5<x<0.5\left(\mathrm{R}^{2}=0.988\right)$;

Case 3: $y_{3}=-0.5495 x^{5}+1.5527 x^{4}-1.2653 x^{3}-0.4425 x^{2}+1.2506 x+0.4552 ;-0.5<x<1.0\left(R^{2}=0.997\right)$.

A detailed comparison of the probability of the three cases is listed in Table 7. For all the cases, the probability to be NZEB was $0 \%$ and around $45 \%$ under a mismatch ratio below -0.4 and about 0.0 , respectively. In general, a similar trend of probability was found in Case 1 and Case 2 . When the mismatch ratio was more than 0.6, the probability in Case 1 and Case 2 could hit the target of $100 \%$, whilst it was a mismatch ratio of over 1.0 that could ensure the probability of $100 \%$ in Case 3 . In addition, it seems that the probability in Case 3 was higher than that in Case 1 and Case 2 when the mismatch ratio was between -0.4 and 0.0 . However, it was reversed when the mismatch ratio was between 0.0 and 0.8 .

(a)
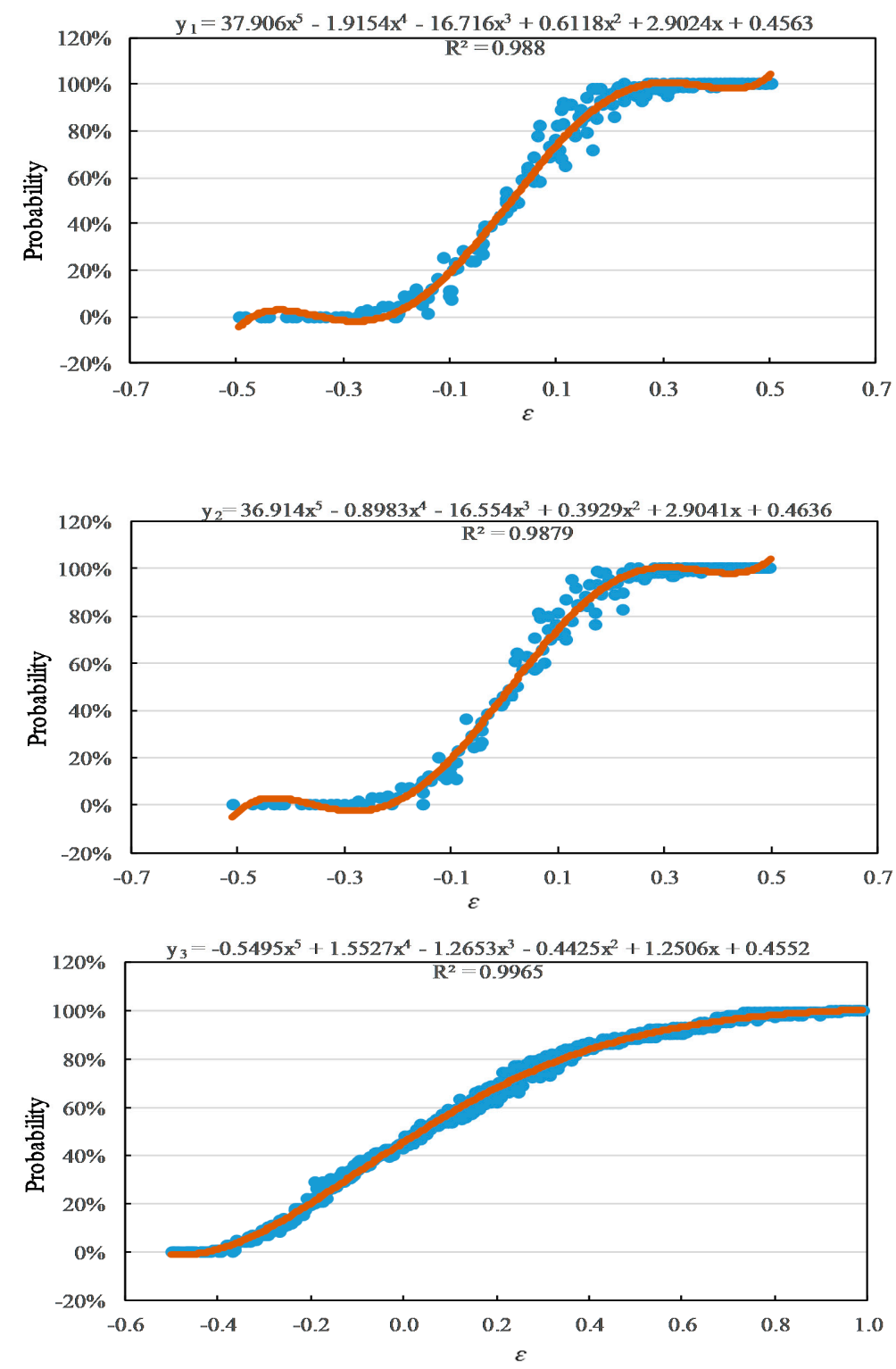

Figure 15. Mismatch ratio and the corresponding probability of NZEB in (a) Case 1; (b) Case 2; (c) Case 3. 
Table 7. Optimal size and performance for NZEB.

\begin{tabular}{cccc}
\hline$\varepsilon$. & C1 & C2 & C3 \\
\hline$<-0.4$ & $0.0 \%$ & $0.0 \%$ & $0.0 \%$ \\
-0.4 & $2.7 \%$ & $2.3 \%$ & $1.1 \%$ \\
-0.2 & $1.9 \%$ & $1.8 \%$ & $20.0 \%$ \\
0.0 & $45.6 \%$ & $46.4 \%$ & $45.5 \%$ \\
0.2 & $93.7 \%$ & $93.8 \%$ & $68.0 \%$ \\
0.4 & $98.6 \%$ & $98.4 \%$ & $83.8 \%$ \\
0.6 & $100.0 \%$ & $100.0 \%$ & $93.1 \%$ \\
0.8 & $100.0 \%$ & $100.0 \%$ & $98.1 \%$ \\
$\geq 1$ & $100.0 \%$ & $100.0 \%$ & $100.0 \%$ \\
\hline
\end{tabular}

\section{Conclusions}

This study proposed a robust design optimization method for renewable energy systems in net-zero energy buildings (NZEBs) by considering the reliability of generation systems based on the Markov chain model. To investigate the effect of the reliability of generation systems on system selection and NZEB performance, three cases (i.e., Case 1: Deterministic, Case 2: Markov chain without the aging effect, Case 3: Markov chain with the aging effect) were designed and compared under a 100-years operation. Design optimization was conducted in terms of the annual total cost and grid interaction index, respectively. Based on the results, several conclusions can be drawn as follows:

(1) In terms of the annual energy balance, the optimal size of RES in Case 3 (i.e., mismatch ratio of above $90 \%$ ) was much larger than that in Case 1 and Case 2 (i.e., mismatch ratio of below 50\%). Meanwhile, the aging effect of the generation system was identified to be a vital factor in system selection and the expected target for NZEB.

(2) In terms of the 100-years energy balance, a much smaller RES size was required, especially in Case 3, where a remarkable reduction of mismatch ratio was found from $92 \%$ to $3 \%$. Meanwhile, the number of years for net-zero energy balance was also identified to be an essential factor in system selection and expected target for NZEB.

(3) The fitting formula with a good coefficient of determination was obtained to describe the relationship between the mismatch ratio and the probabilities for each case. In all cases, the probability to be NZEB was $0 \%$ under a mismatch ratio of below -0.4 and was around $45 \%$ under a mismatch ratio of 0.0 . In addition, a mismatch ratio of over 1.0 was required to ensure a $100 \%$ NZEB in Case 3 when considering the aging effect, and it was over 0.6 that required for a 100\% NZEB in Case 1 and Case 2.

The reliability assessment of the generation system, considering the aging effect, was investigated for the optimal design of renewable energy systems in net-zero energy buildings, while the reliability of energy systems such as chillers and similar were ignored in this study. Further research can be conducted by considering reliability from both the energy generation system and energy consumption systems.

Author Contributions: Conceptualization, Y.L., M.S.A.-A., H.G.; methodology, Y.L., M.A., Z.A.K., M.S.A.-A.; software, Y.L., H.G.; validation, Z.A.K., M.A.; formal analysis, Z.K., M.A., M.I.; writing, all authors contributed jointly; editing, Z.A.K., M.I., funding acquisition, Y.L., Z.A.K., M.A. All authors have read and agreed to the published version of the manuscript.

Funding: This research received funding from the National Natural Science Foundation of China (Project No. 51608001) and Youth Talent Program in Anhui University of Technology (Project No. DT18200013) to carry out the research work reported in this paper.

Acknowledgments: The authors also acknowledge the support provided by the China Scholarship Council (CSC) and research support from the Mirpur University of Science and Technology, Mirpur (A.K.), Pakistan.

Conflicts of Interest: The authors declare no conflict of interest. 


\section{Nomenclature}

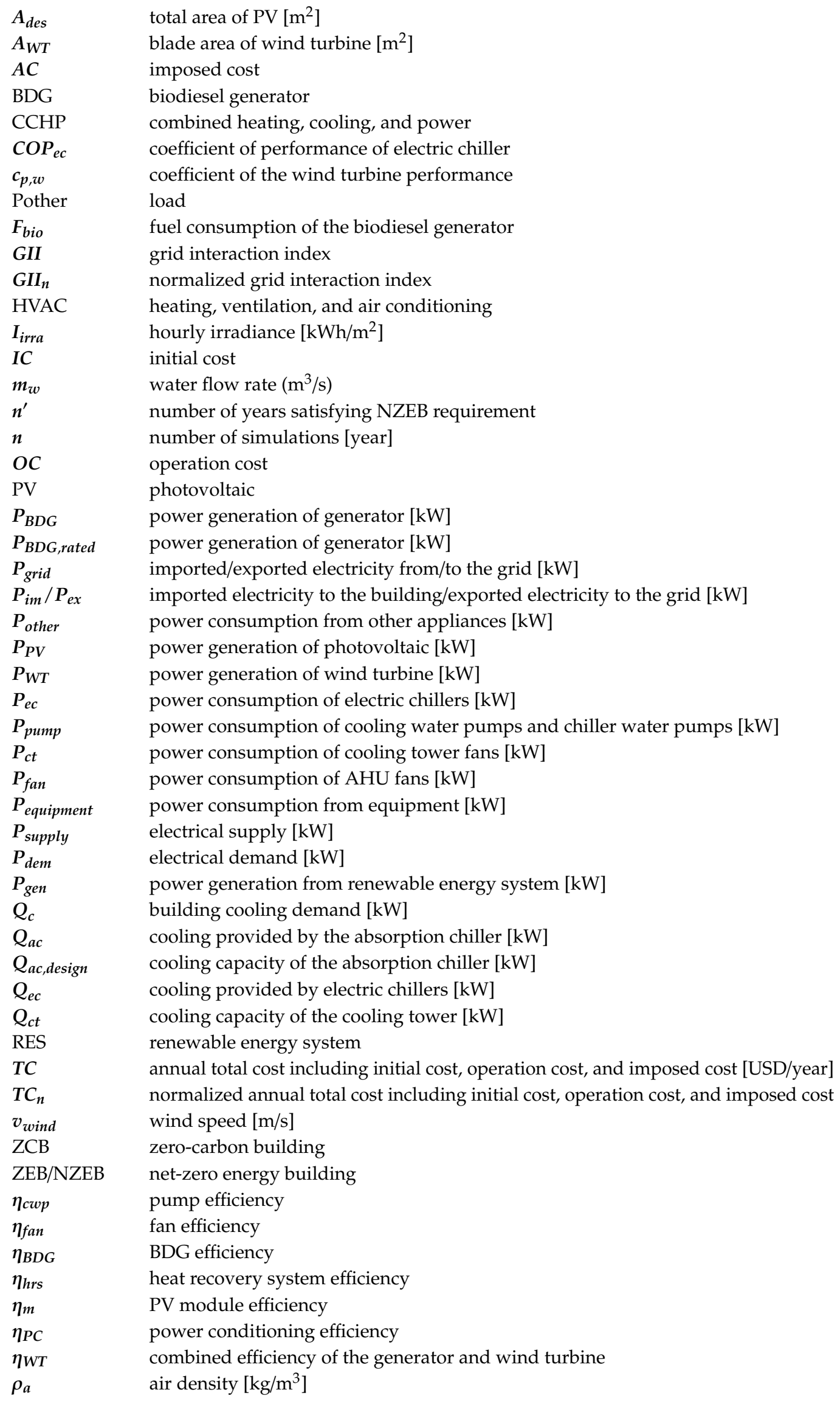




$\begin{array}{ll}v a & \text { air flow rate }\left[\mathrm{m}^{3} / \mathrm{s}\right] \\ \varepsilon & \text { mismatch ratio } \\ \lambda_{r} & \text { failure rate }[1 / \mathrm{h}] \\ \mu_{r} & \text { repair rate }[1 / \mathrm{h}] \\ \lambda_{F} & \text { degradation rate of the component }[1 / \mathrm{h}] \\ T W & \text { lifetime of the component [years] }\end{array}$

\section{References}

1. Recast, E.P.B.D. Directive 2010/31/EU of the European Parliament and of the Council of 19 May 2010 on the Energy Performance Of Buildings (Recast). Available online: https://eur-lex.europa.eu/legal-content/en/TXT/ ?uri=CELEX\%3A32010L0031 (accessed on 25 May 2020).

2. Crawley, D.; Pless, S.; Torcellini, P. Getting to Net Zero; National Renewable Energy Laboratory (NREL): Golden, CO, USA, 2009.

3. Thalfeldt, M.; Pikas, E.; Kurnitski, J.; Voll, H. Facade design principles for nearly zero energy buildings in a cold climate. Energy Build. 2013, 67, 309-321. [CrossRef]

4. Rabani, M.; Madessa, H.B.; Nord, N. A state-of-art review of retrofit interventions in buildings towards nearly zero energy level. Energy Procedia 2017, 134, 317-326. [CrossRef]

5. Wu, W.; Skye, H.M.; Domanski, P.A. Selecting HVAC systems to achieve comfortable and cost-effective residential net-zero energy buildings. Appl. Energy 2018, 212, 577-591. [CrossRef] [PubMed]

6. Costanzo, G.T.; Zhu, G.; Anjos, M.F.; Savard, G. A system architecture for autonomous demand side load management in smart buildings. IEEE Trans. Smart Grid 2012, 3, 2157-2165. [CrossRef]

7. Lu, Y.; Wang, S.; Zhao, Y.; Yan, C. Renewable energy system optimization of low/zero energy buildings using single-objective and multi-objective optimization methods. Energy Build. 2015, 89, 61-75. [CrossRef]

8. Huang, Z.; Lu, Y.; Wei, M.; Liu, J. Performance analysis of optimal designed hybrid energy systems for grid-connected nearly/net zero energy buildings. Energy 2017, 141, 1795-1809. [CrossRef]

9. Zhang, S.; Sun, Y.; Cheng, Y.; Huang, P.; Oladokun, M.O.; Lin, Z. Response-surface-model-based system sizing for Nearly/Net zero energy buildings under uncertainty. Appl. Energy 2018, 228, 1020-1031. [CrossRef]

10. Maheri, A. Multi-objective design optimisation of standalone hybrid wind-PV-diesel systems under uncertainties. Renew. Energy 2014, 66, 650-661. [CrossRef]

11. Lu, Y.; Zhang, X.-P.; Huang, Z.; Lu, J.; Wang, D. Impact of introducing penalty-cost on optimal design of renewable energy systems for net zero energy buildings. Appl. Energy 2019, 235, 106-116. [CrossRef]

12. Yu, Z.J.; Chen, J.; Sun, Y.; Zhang, G. A GA-based system sizing method for net-zero energy buildings considering multi-criteria performance requirements under parameter uncertainties. Energy Build. 2016, 129, 524-534. [CrossRef]

13. Sun, Y.; Huang, P.; Huang, G. A multi-criteria system design optimization for net zero energy buildings under uncertainties. Energy Build. 2015, 97, 196-204. [CrossRef]

14. Lu, Y.; Wang, S.; Yan, C.; Huang, Z. Robust optimal design of renewable energy system in nearly/net zero energy buildings under uncertainties. Appl. Energy 2017, 187, 62-71. [CrossRef]

15. Ma, T.; Yang, H.; Lu, L. A feasibility study of a stand-alone hybrid solar-wind-battery system for a remote island. Appl. Energy 2014, 121, 149-158. [CrossRef]

16. Huang, P.; Huang, G.; Sun, Y. A robust design of nearly zero energy building systems considering performance degradation and maintenance. Energy 2018, 163, 905-919. [CrossRef]

17. Maleki, A.; Khajeh, M.G.; Ameri, M. Optimal sizing of a grid independent hybrid renewable energy system incorporating resource uncertainty, and load uncertainty. Int. J. Electr. Power Energy Syst. 2016, 83, 514-524. [CrossRef]

18. Bekele, G.; Tadesse, G. Feasibility study of small Hydro/PV/Wind hybrid system for off-grid rural electrification in Ethiopia. Appl. Energy 2012, 97, 5-15. [CrossRef]

19. Hassoun, A.; Dincer, I. Development of power system designs for a net zero energy house. Energy Build. 2014, 73, 120-129. [CrossRef]

20. Ekren, O.; Ekren, B.Y. Size optimization of a PV/wind hybrid energy conversion system with battery storage using simulated annealing. Appl. Energy 2010, 87, 592-598. [CrossRef] 
21. Lu, J.; Wang, W.; Zhang, Y.; Cheng, S. Multi-objective optimal design of stand-alone hybrid energy system using entropy weight method based on HOMER. Energies 2017, 10, 1664. [CrossRef]

22. Harkouss, F.; Fardoun, F.; Biwole, P.H. Multi-objective optimization methodology for net zero energy buildings. J. Build. Eng. 2018, 16, 57-71. [CrossRef]

23. Karki, R.; Billinton, R.; Verma, A.K. Reliability Modeling and Analysis of Smart Power Systems; Springer Science \& Business Media: New York, NY, USA, 2014; ISBN 8132217985.

24. Alvarez-Alvarado, M.S.; Jayaweera, D. Aging Reliability Model for Generation Adequacy. In Proceedings of the 2018 IEEE International Conference on Probabilistic Methods Applied to Power Systems (PMAPS), Boise, ID, USA, 24-28 June 2018; pp. 1-6.

25. Alvarez-Alvarado, M.S.; Jayaweera, D. Reliability model for a Static Var Compensator. In Proceedings of the 2017 IEEE Second Ecuador Technical Chapters Meeting (ETCM), Salinas, Ecuador, 16-20 October 2017; pp. 1-6.

26. Alvarez-Alvarado, M.S.; Jayaweera, D. A New Approach for Reliability Assessment of a Static V ar Compensator Integrated Smart Grid. In Proceedings of the 2018 IEEE International Conference on Probabilistic Methods Applied to Power Systems (PMAPS), Boise, ID, USA, 24-28 June 2018; pp. 1-7.

27. Gen, B. Reliability and Cost/Worth Evaluation of Generating Systems Utilizing Wind and Solar Energy. Ph.D. Thesis, University of Saskatchewan, Saskatoon, SK, Canada, 2005.

(C) 2020 by the authors. Licensee MDPI, Basel, Switzerland. This article is an open access article distributed under the terms and conditions of the Creative Commons Attribution (CC BY) license (http://creativecommons.org/licenses/by/4.0/). 